\title{
Effect of Low Temperature Stress on the Hemerocallis Fulva
}

\author{
Huang Changbing ${ }^{1,2}$, Qian Jianlin², Qiu Hengjia'², Zhang Huanchao \\ ${ }^{1}$ Nanjing Forestry University College of Forestry, Nanjing 210037, China \\ ${ }^{2}$ Suzhou Polytechnic Institute of Agriculture, Suzhou 215008, China \\ hcb1025@126.com
}

Keyword: hemerocallis fulva; anti-reversion force; low temperature stress;

\begin{abstract}
The suitable temperature is the necessary condition of plant growth and development; the temperature is too high or too low will have harmful effects on plant growth. Low temperature damage to plants is called cold damage, and high temperature damage to plants called heat damage. According to the degree of low temperature and the damage condition of plants, cold injury and chilling injury are divided. The adaptability and resistance of plants to low temperature are called cold hardiness of plants. The plant's adaptability to high temperature and its resistance to heat are called thermal resistance of plants. The winter blight of the lily has influenced its application and popularization in the garden. The cold resistance of 31 lily varieties was studied, which provided reference for landscape designers. The observation shape was observed in winter, and the measured results of water content, bound water content and relative conductivity of the leaves were compared. There were great differences in the winter viewing period of 31 varieties, of which 7 varieties were evergreen in winter, but there were also differences in cold hardiness. Among the 7 evergreen varieties, 4 are excellent, suitable for viewing in winter, and can be widely used in gardens.
\end{abstract}

\section{Low-temperature Stress}

At zero temperature, although there is no icing phenomenon, but can cause the physiological barrier of warm plants, so that the plant injury or even death. In our country, the chilling injury mainly occurs in early spring and late autumn season, the main harm is in the seedling stage, grain or fruit maturity. The seedlings of rice, cotton, corn and spring sowing vegetables often encounter the harm of the freezing point or above, resulting in rotten seeds, dead seedlings or stiff seedlings. Fruit trees with long leaves or flowering will cause a lot of falling flowers when they are cold, so that the setting rate is lower. The three-leaf rubber trees growing in South China are affected by irregular cold currents in winter, withered branches and even whole plants, which is the main factor affecting the development of rubber trees to the north.

The chilling injury can be divided into two types according to the reaction rate of plant to chilling injury. A direct injury, that is, when the plant is affected by low temperature, at most within a day that there is plaque and necrosis, the impact of the invasion of cells, directly damaging the activity of protoplasm. The other is indirect injury, that is, the plant is affected by low-temperature, plant morphology is not unusual, at least within a few days after the tissue soft, wilting, and this is due to low temperature caused by metabolic disorders, biochemical slow changes in cell damage. Photosynthesis weakened, respiratory metabolic disorders, cell membrane system damage, root absorption capacity decreased, metabolic disorder. Generally, the measures to improve the cold resistance of plants are: to cultivate cold resistant varieties, plant low-temperature exercise, the use of chemical induction to improve plant cold resistance, rational fertilization.

Under freezing temperature, the damage caused by icing in plant tissues is called frost damage, and the adaptability and resistance of plant to frost damage are known as frost resistance of plants.

The temperature range caused by freezing injury is related to plant species, organs, reproductive period and physiological state. The degree of frost damage of plants is also related to the cooling range, the temperature duration and the thawing speed. When the cooling amplitude is too large, the frost time is long, the thawing time is fast, and the plant suffers seriously; if the slow freezing or 
thawing slowly, the plant suffers less. The general symptoms of plant damage are: blade such as scald, tissue due to cell loss of pressure to soften, leaf color into brown, serious death.

Damage to plants is mainly caused by the freezing of tissues or cells, including the freezing of intercellular space and the freezing of cells. Because of the degree and speed of temperature decline, plant body icing in different ways, the victims are also different.

Cell gap Icing Damage: When the ambient temperature slows down, so that the temperature in the plant to the freezing point, the cell gap between the water began to freeze, that is, intercellular icing. Intercellular icing does not necessarily kill the plant, and most plants freeze slowly after freezing to restore normal growth

Intracellular icing damage: when the ambient temperature drops abruptly, not only the cell space icing, the cell will also freeze, the general first in the protoplasm in the icing, and then in the bubble ice, the small amount of ice crystals in the cell, the number of their formation will be biofilm, cell and matrix structure irreversible mechanical damage. The destruction of the protoplasm must lead to metabolic disorders and cell death.

\section{Hemerocallis Fulva}

Hemerocallis fulva (scientific name: Hemerocallis fulva) is Herbs Perennial. Day Lily alias Numerous, there are "Lily", "Day Lily", "Forget Worry Grass", "Yi Men Grass", "cure Worry", "Deer Arrow" and other names, in English called Day Lily "Tiger Lily" (Tiger Lily, this is also Curly Dan's English name). When edible, many are called "The Golden Lily" (Golden Needle). Its leaf shape is flat-shaped long line type, and the underground stem has traces of poison, not directly edible. The flower shape is a slender green flowering branch in the flowering stage, the color orange, the located is very long, assumes the tube like the lily flower. The fruit of the knot has wings. Common cultivation throughout the country, the southern provinces of Qinling Mountains have wild.

Although the origin of flowers and plants in China, but has not been improved for a long time. After the 1930 's, some American botanical gardens, horticultural enthusiasts collected in China, Japan and other countries produced by the plant, for crossbreeding breeding, now has reached more than million species, become an important ornamental and cut flowers, but also the most varieties of lily flower category.

At the same time, the Lily is the mother flower of China.

The sun lilies like the warm and humid environment. The soil is the best with a little stickiness. It can be cultivated in Tian Kan Bijie, ditch, residence, etc. October-November after the ground withered or spring plants before germination, the whole plant dug up, every 2.3 is divided into a bundle. Cave Deep $17-20 \mathrm{~cm}$, each point planted a clump, the root to the four tiles, cover soil compaction. Watering or pouring water on human and animal dung. Since the second year, weeding and fertilizing 3 times a year, the first time in March when the emergence of the second in June before flowering, the third in October after the fall of the seedlings, after each weeding, the use of human and animal manure.

\section{Environmental Effect}

Temperature. The weather is strong, hardy; north China can open the winter, adaptable, moist and drought-tolerant, sunny and half shade. The soil selectivity is not strong, but is rich in humus; the drainage good moist soil is advisable.

Soil. The selectivity of the soil is not strong, but it is rich in humus, drainage good moist soil is advisable, adapt to grow at an altitude of 300-2500 meters.

\section{Method}

The leaf blight of the test material during overwintering was observed and recorded 11 times. During the investigation, each random sampling of the growth of a consistent number of blades, 
using a drilling device to take 150 pieces, put 3 weighing bottles, bottle weighing after placing $105{ }^{\circ} \mathrm{C}$ to kill the tissue, and then $80 \sim 90^{\circ} \mathrm{C}$ drying, measuring its water content. Use a drill to take 150 pieces, 3 test tubes, plus ml deionized water, shaking min, conductivity meter method to measure conductivity, $100{ }^{\circ} \mathrm{C}$ boiling. With a drilling device to take 150 pieces, 3 weighing bottles, said after the quality of $60 \%$ sucrose solution $5 \mathrm{ML}$, and then weighed separately, in the dark place $4 \sim 6 \mathrm{H}$, uninterrupted shaking, using Abbe refract meter to measure the sucrose concentration and the original sucrose concentration, calculate the free water content.

\section{Climatic Characteristics of the Test}

According to the Suzhou Meteorological Bureau statistics, Suzhou October 2013 average temperature of $17.8{ }^{\circ} \mathrm{C}$, November average temperature of $9.4{ }^{\circ} \mathrm{C}$, a very short period of freezing, the lowest temperature $-2^{\circ} \mathrm{C} ; 12$ monthly average temperature of $6.7{ }^{\circ} \mathrm{C}$, the late emergence of continuous $0{ }^{\circ} \mathrm{C}$ around the low temperature, and lasted longer, the limit temperature of $4{ }^{\circ} \mathrm{C}$; The average temperature in January was $6.9{ }^{\circ} \mathrm{C}$, the temperature recovered from late December, and $7.9{ }^{\circ} \mathrm{C}$ in late February, and the temperature began to pick up markedly.

\section{Conclusion}

\subsection{Comparison of leaf green periods}

31 varieties of the large flower of the whole winter viewing period performance varies greatly, the variety of gold dolls, hybrid varieties 0630, Souxu, Suo, hybrid varieties nz-51, beautiful women and clubs on December 10 has withered; The varieties of Stradeo, Gutong, hybrid 0812, Kingdee red stripes, self, Jin Yu and Tang winter leaves do not wither, the whole winter ornamental good. Comparison of permeability of evergreen cultivars

\subsection{Comparison of permeability of evergreen cultivars}

Cell membrane permeability is an important physiological index of plant cold hardiness, the higher the relative permeability, the more serious the damage of plant somatic cells is. The change of relative permeability under different temperature conditions reflects the resistance of a plant to temperature change. Under low temperature conditions, the relative permeability was negatively correlated with the cold hardiness of plants. The permeability of the cells was calculated by measuring the conductivity of plant blades continuously. Evergreen 7 varieties, with the continuous decrease of temperature, in December, the 1th time of continuous low temperature, the variety of Stradeo, Gutong, hybrid 0812, Kingdee red, self and Jin Yu blade permeability to achieve the largest, and then began to reduce, with the new leaf of the long, February middle and return to normal level. Among these 7 varieties, the Stradeo change amplitude is the smallest, variety Gutong, hybrid variety 0812, the largest penetration rate of Kingdee is not more than 35\%, and Tang change amplitude is the biggest, more than 55\%, Jin Yu variety second. This shows that in these 7 varieties, the cold hardiness of the most strong, and varieties of Gutong, hybrid 0812, Kingdee red lines, the worst cold resistance in Tang.

\subsection{Comparison of water content in leaves of evergreen cultivars}

Since late October, every $d$ has measured the moisture content of the leaves. It can be seen that the moisture content of the leaves of 7 evergreen cultivars decreases with the passage of time, but the overall difference is not large, among which the variation of water content is the most, and the water content of variety Gutong is the second. By mid-February, the water content returned to normal levels. It shows that the water content of the leaves has no obvious correlation with cold hardiness.

The content of bound water in plants is positively correlated with the cold hardiness of plants, the smaller the ratio of free water/bound water, the more viscous the protoplasm, the stronger the ability of restraining the movement of water molecules, the lower the possibility of dehydration and 
icing, the lower the possibility of plant cold and freezing injury at low temperature. Jin Yu and Tang 2 varieties were weaker than other varieties, and the cold hardiness was the weakest.

(1) In the low temperature treatment experiment, different large flower and winter lily variety winter performance difference is very big, most varieties cannot maintain evergreen, generally in the early December not cold varieties that have been all leaves off. Some varieties in Suzhou can keep the winter leaves do not dry, ornamental more withered varieties strong.

(2) Through the low temperature test of the selected varieties, it was found that 7 varieties were kept green in winter, but the cold resistance was different. After analysis, whether the cell permeability or free water/bound water index of the determination, Stradeo, Gutong, hybrid 0812 and Kingdee red lines of these 4 varieties showed significantly superior to other varieties, the variety of Tang performance is the weakest. But in the water content index measurement result, the difference of several varieties is not obvious.

(3) The above measurement can only show that the plant has certain resistance to low temperature, but the half lethal temperature of the blade still needs to be calculated.

(4) Synthesize each index, get the following conclusion, the Stradeo, Gutong, hybrid 0812, Kingdee red stripe, self, Jin Yu and Tang these 7 varieties in Suzhou are not withered in the winter, and can be cultivated in the south of middle and lower reaches of the Yangtze River.

\section{Acknowledgements}

Jiangsu modern agriculture (flower) industry technology system integration innovation center (No. SXGC [2017] 241).

Integration and popularization of potted flower cultivation techniques (No. SXGC [2017] 244).

\section{References}

[1] Li H S. Physiological and biochemical experiments of plants [M]. Beijing: Higher Education Press, 2000.

[2] Wang R, Ma F, Li Y f. Effects of low temperature stress on praline, MDA content and conductivity of maize seedlings [J]. Journal of Northeastern Agricultural University, 2008, 39 (5): 20-23.

[3] A study on cold hardiness of Wang Y q Rose [J]. Gardening and seedling, 2012, 07:32-34, 46.

[4] Y c q. Study on the correlation between plant water content and plant cold hardiness [J]. Inner Mongolia Agricultural Science and Technology, 2010 (2): 60.

[5] Wang H, S g, S, ET. Study on agro meteorological disasters in South Donating Lake area and countermeasures for disaster prevention and mitigation [J]. Research on agricultural Disasters, 2014 (4): 36-41, 55.

[6] $\mathrm{T} \mathrm{X} \mathrm{m,} \mathrm{Zhang} \mathrm{Xi}$, song gorgeous, and so on. Wei h the construction of Agricultural meteorological service platform with low temperature and freezing damage [J]. Research on agricultural Disasters, (Z2): 50-51, 56.

[7] The research progress of cold-resistant biochemistry of Jing j, a new high-tech, 2011

[8] W w h Plant Physiology (second edition) Beijing: Science Press, 2008, 135-186

[9] Ma Y y, Shao, Zhang Wen N Plant A review of research on low temperature stress of plants Anhui Agricultural Sciences, 2012,40 (12): 7007-7008,7099 